\title{
TRANSLATORS' PREFACE.
}

In the two years that have followed the translation of the First Volume of the Grundriss der vergleichenden Sprachwissenschaft by Dr. (now Professor) Joseph Wright, the difficulty of the task has sensibly diminished. The methods and the nomenclature of the scientific school of Comparative Philology have found their way more and more into the work of English teachers, and it has become far easier to decide what innovations can, and what cannot be reconciled with established usage. Such words, for example, as 'thematic', 'ablaut', 'analogical', 'contamination, 'proethnic' are completely naturalised. The last we have universally adopted as the clearest equivalent of the German ur-prefixed to the name of a group of languages: 'proethnic Greek' is Greek older than the rise of its various dialects; 'proethnic Indo-Germanic', or more simply where there is no ambiguity, 'the proethnic language' is the parent of the various families of Indo-Germanic speech.

On the other hand the new subject-matter of the present volume involves new difficulties. On almost every other page of the original the word Grundform is used to denote the original form from which any particular word has been developed by phonetic change, and considering the frequency of its occurrence we could see no alternative but to adopt it bodily into English. Again some such expressions as 'fertile' (produktiv) and 'extended' (erweitert) were indispensable to describe the history of the different suffixes. The process of deriving a feminine form 
from the mascnline stem of an adjective (Germ. Motion) we have called 'differentiation'. To express the change by which a substantival compound becomes an adjective, or in terms of Sanskrit grammar, by which a karma-dharaya-compound becomes a bahu-vrihi German scholars have created a new verb mutieren, i. e. the Lat. mutare; the word 'epithetised' which is used for the first time in this translation is an attempt to describe the nature of the change a little more explicitly. Thus in English blackbird is a simple or 'non-epithetised' compound, Greatheart, rosy-fingered,

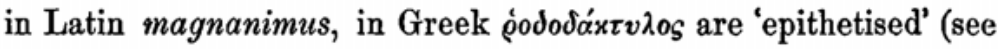
p. 92). The ambiguity of the word 'formation' which like the German Bildung does double duty, to denote sometimes an abstract process and sometimes its concrete result, is a source of considerable difficulty, which might well be avoided by using such a term as 'formate' to express the second meaning; and the convenience of words like trans-formate, re-formate afformate (Umbildung, Neubildung, Nachbildung) is at once obvious. But the change is not absolutely necessary and therefore, since this is a book of general reference, it seems fairer to the reader to suggest it in the Preface rather than to introduce it directly into the text; perhaps however we may assume the licence in the following volumes.

A small but perpetually recurring difficulty of which the reader should be warned, has been the translation of the preposition $z u$ in its technical sense, for which we have no exact equivalent in English, except such phrases as 'directly related to', 'connected in accidence with' and these would be, to say the least, a little wearisome, if they appeared twenty times on a page. It really covers several shades of meaning; in 'ama $\bar{a} \bar{z} \mathrm{zu}$ amó 'tul̄ zu fer $\vec{o}$ it means used as a tense of; in 'ansătus' zu ansa', a derivative of; in 'modestus zu modus', used as a derivative of; in 'Lat. inclutus zu Gr. $x \lambda v^{\omega} \omega$ ', containing the root of; and so on. The nearest English equivalent in the first two cases would be the preposition from, in which there is a more serious ambiguity, used as it is to denote both historical and logical connexion, 'tuli from the root tel-', 'tuli from ferō'. 
Sometimes of course the two coincide, but only in the case of words of which the first was in use in the form in which we quote it before the second came into existence. suavior 'comes from' suavis historically as well as logically because it is a special formation in Latin (in place of the Indo-Germanic stem *suad-iinos-); whereas the genitive patris can only be said to 'come from' the nominative pater in the logical sense, not the historical, since both are descended from proethnic forms. The rule therefore that we have adopted has been to write from in the logical sense only where there can be no possible doubt that that is its meaning; where there would have been any danger that the reader should infer from it a historical, derivative relation that was not implied in the German, we have used beside. Thus in the examples given above we should render 'tuli from feró ' but 'modestus beside modus' (see p. 418). The line is of course hard to draw, but for safety's sake, we have used beside in all cases of doubt. To do so universally, i. e. to have written always 'patris beside pater' instead of 'from pater' seemed a little pedantic. On the other hand from has of course its proper derivative significance in such phrases as 'ansatus from $a n s a$, where in German von and $z u$ are used indifferently. The German aus connecting a form with its immediate phonetic antecedent, e. g. 'Lat. fissus aus 'fid-to-s' we have followed prevailing usage in rendering by for, 'fissus for *fid-to-s'. The reader will find that for is used only in this sense of direct phonetic connexion; to describe an analogical substitution (Germ. für) we have regularly kept to 'instead of'.

In minor matters, such as abbreviations, and details of printing we have followed English rather than German precedent. For obvious reasons however we have retained the order of the original in such phrases as 'Gr. Att. ïллоs' 'Skr. Ved. śray-iștha-' (cf. p. 244), where they occur in a list of forms from different languages. But we have ventured to retain the symbol : which occurs on every page, and denotes that the forms that it connects stand in a definite relation to one another, and this, when it is not otherwise explained by the context, is always 
one of regular phonetic correspondence; for instance it is invariably used to connect an Indo-Germanic form with the words which represent it in the derived languages e. g. Idg. *kiku-tó-s: Skr. śru-tá-s, Gr. $x \cdot \lambda v-\tau o$-s etc. A modification of this symbol, for which it was equally impossible to find a substitute, ': cp.' means 'partly related to' 'in some respects to be compared with'; it is employed where the forms compared are not completely parallel, but only to some extent, e. g. on p. $39, \S 23$ 'Skr. $a$-a $a p t a-s$ : cp. Lat. in-eptu-s'; here the two words are parallel, but not identical, as the Latin form is derived from *ap-to-, the Sanskrit from ${ }^{*} a p$-t $\delta$-, see Vol. I $\S 97,3$ p. 91 . Similarly on p. $60, \S 34$

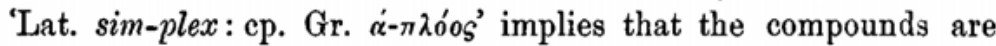
parallel, but identical only in their first member; p. 193, § 75

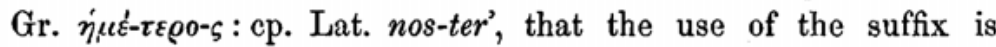
the same in both. It would be difficult to enumerate all the varieties of positive meaning that may be implied by this practically colourless symbol; to remove it altogether would be to re-edit the whole Grammar, not to translate it. The symbol : is also placed at the end of a general statement which is immediately followed by a list of illustrative examples, but otherwise it is not used as a mark of punctuation. On the other hand where the scientific brevity of the original made the connexion of the argument a little difficult to follow, so that sometimes the meaning of a whole paragraph turned on the significance of a comma or a bracket, we have felt less scruple in giving it more explicit expression.

In the first hundred pages and in the sections on the Meaning of the Suffixes, the reader will find a few additions to the text for which the translators are responsible. With Prof. Brugmann's permission we have inserted illustrations from Modern English beside his own from Modern German, where the latter are given to illustrate some general principle. These interpolations are all enclosed in square brackets.

At his request we have departed from Dr. Wright's usage in one important respect by using Old Church Slavonic instead of Old Bulgarian as the name of the language of the 
Slavonic apostles Cyril and Methodius. We hesitated for some time between 'Welsh' and 'Cymric', but decided on the whole to keep the latter in conformity with the first volume. The Corrections and Additions' of the German edition are embodied in the text, together with several other minor alterations, mainly of misprints, which Prof. Brugmann has sent us. To him we would offer our hearty thanks for his constant help in matters of difficulty. We owe to Dr. Wright's courtesy a list of Corrigenda in Volume I.

The translation is a joint work throughout, but Mr. Conway is everywhere responsible for its final form, as Mr. Rouse will be in the remaining volumes, which we hope will follow the parts of the German edition as they appear, at much shorter intervals than has been possible so far.

The present volume has demanded a year's continuous work and a good deal of anxious consideration from us both. But we shall be more than rewarded if it can do anything to extend the share which English-speaking students can claim in the marvellous increase of exact knowledge which the book itself records. It is the boast of modern discovery to have made the world more thinkable and human life more full of meaning in a thousand ways; and before the century reaches its close, Comparative Philology, that is, the History of Language, will have attained no mean rank in the great sisterhood of sciences whose task is to explore the history of man.

R. Seymodr Conway.

W. H. D. Rouse.

Cambridge, Aug. 1. 1890. 